\title{
Solar irradiance at the earth's surface: long-term behavior observed at the South Pole
}

\author{
J. E. Frederick and A. L. Hodge \\ Department of the Geophysical Sciences, University of Chicago, Chicago, Illinois, USA \\ Received: 24 September 2010 - Published in Atmos. Chem. Phys. Discuss.: 3 November 2010 \\ Revised: 20 January 2011 - Accepted: 3 February 2011 - Published: 11 February 2011
}

\begin{abstract}
This research examines a 17-year database of UV-A $(320-400 \mathrm{~nm})$ and visible $(400-600 \mathrm{~nm})$ solar irradiance obtained by a scanning spectroradiometer located at the South Pole. The goal is to define the variability in solar irradiance reaching the polar surface, with emphasis on the influence of cloudiness and on identifying systematic trends and possible links to the solar cycle. To eliminate changes associated with the varying solar elevation, the analysis focuses on data averaged over 30-35 day periods centered on each year's austral summer solstice. The long-term average effect of South Polar clouds is a small attenuation, with the mean measured irradiances being about 5-6\% less than the clear-sky values, although at any specific time clouds may reduce or enhance the signal that reaches the sensor. The instantaneous fractional attenuation or enhancement is wavelength dependent, where the percent deviation from the clear-sky irradiance at $400-600 \mathrm{~nm}$ is typically 2.5 times that at $320-340 \mathrm{~nm}$. When averaged over the period near each year's summer solstice, significant correlations appear between irradiances at all wavelengths and the solar cycle as measured by the $10.7 \mathrm{~cm}$ solar radio flux. An approximate $1.8 \pm 1.0 \%$ decrease in ground-level irradiance occurs from solar maximum to solar minimum for the wavelength band $320-400 \mathrm{~nm}$. The corresponding decrease for $400-600 \mathrm{~nm}$ is $2.4 \pm 1.9 \%$. The best-estimate declines appear too large to originate in the sun. If the correlations have a geophysical origin, they suggest a small variation in atmospheric attenuation with the solar cycle over the period of observation, with the greatest attenuation occurring at solar minimum.
\end{abstract}

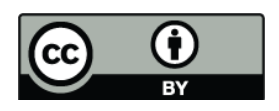

Correspondence to: J. E. Frederick (frederic@uchicago.edu)

\section{Introduction}

Solar radiation reaching the Earth's surface varies over a range of spatial and temporal scales. These variations include erratic short-term fluctuations associated with local cloudiness, longer-term changes in atmospheric attenuation on regional or global scales (Wild, 2009), and changes in the extraterrestrial irradiance over the 11-year solar cycle (Willson, 1997; Fröhlich, 2009) and the very long time scale of stellar evolution (Gough, 1981).

The depletion of springtime stratospheric ozone amounts over Antarctica motivated concerns over changes in biologically relevant solar ultraviolet radiation during the 1980's and 1990's (Weiler and Penhale, 1994). Since that time longterm measurements have been conducted at both high and middle latitudes (e.g. Liao and Frederick, 2005; Hicke et al., 2008) where the emphasis was on the influence of changing ozone amounts. Although ultraviolet radiation is clearly a significant environmental parameter, enhanced interest in the Earth's climate system as a whole has focused attention on a wider range of the sun's emission. It is increasingly important to characterize all portions of the extraterrestrial and surface solar irradiance so as to define variations over all time scales. Issues of relevance here include variations inherent in the sun, the role of cloudiness, and any factor that influences the transmission of the Earth's atmosphere (Wild, 2009).

This research examines the 17-year database of UV-A and visible solar irradiances obtained by a scanning spectroradiometer located at the South Pole, Amundsen-Scott Station $\left(90^{\circ} \mathrm{S}\right)$. Emphasis is on wavelengths from 320 to $600 \mathrm{~nm}$ where absorption by ozone is not a major factor in determining the ground-level irradiance. The goal of this work is to define the magnitude and characteristics of variability in solar irradiance reaching the South Polar surface near summer solstice, with an emphasis on the influence of cloudiness and on identifying systematic trends and possible links to the solar cycle. 


\section{The dataset}

This work considers measured irradiances integrated over the wavelength bands $320-340 \mathrm{~nm}, 340-360 \mathrm{~nm}, 360-400 \mathrm{~nm}$, and $400-600 \mathrm{~nm}$ expressed in $\mathrm{W} \mathrm{m}^{-2}$. The time period of interest extends from December 1992 to January 2009. All measured irradiances are accompanied by calculated values appropriate to clear skies using column ozone amounts derived from the spectroradiometer data (Bernhard et al., 2003). Details of the calculations appear in Bernhard et al. (2004).

The instrument is part of the National Science Foundation's Ultraviolet Radiation Monitoring Network, operated by Biospherical Instruments, Inc. The sensor is a scanning spectroradiometer consisting of a quartz window and diffuser plate at the optical entrance, a double monochromator, a photomultiplier as the detector, and associated electronics. The spectral resolution is approximately $1.0 \mathrm{~nm}$. On-site personnel perform calibrations using standard lamps on a periodic basis (Bernhard et al., 2008). Special attention has focused on developing an uncertainty budget for the measurements, including corrections for an imperfect cosine response (Bernhard et al., 2004). The measurements represent the sum of direct and diffuse downward solar spectral irradiances from $280 \mathrm{~nm}$ to $600 \mathrm{~nm}$ in wavelength. Further details of the instrument and the data processing appear in Booth et al. (1994) and Bernhard et al. (2004).

The solar irradiance incident on a horizontal surface is a sensitive function of solar zenith angle (SZA), and any analysis of variability in irradiance must control for changes in SZA. The South Pole is distinguished by the fact that the SZA is essentially constant during an extended period around the December solstice of each year. To utilize this fact, we use only irradiance data collected when the SZA was within $1^{\circ}$ of its annual minimum value. This corresponds to dates from 7 December through 8 January, defined here as a "solstice period" and labeled by the calendar year which contains December. For example, the 2003 solstice period extends from 7 December 2003 to 8 January 2004 during which time the SZA always lies in the range 66.56 to $67.56^{\circ}$. The entire dataset consists of 17 consecutive solstice periods, 1992 through 2008, with a total of 37173 irradiance measurements in each wavelength band. Although data exist for the 1991 solstice period, the observations are contaminated by excess atmospheric aerosols associated with the eruption of the Pinatubo volcano in April of that year. We therefore eliminated this particular solstice period from consideration.

Figure $1 \mathrm{a}-\mathrm{b}$ presents the entire dataset of measured and computed clear-sky irradiances, respectively, for the wavelength band $320-340 \mathrm{~nm}$, where the horizontal axis is the year which labels each solstice period. Figure $2 a-b$ is analogous for the spectral region $400-600 \mathrm{~nm}$. Several features in Figs. 1 and 2 merit comment. First, the clear-sky computed irradiances (Figs. $1 \mathrm{~b}$ and $2 \mathrm{~b}$ ) show a relatively small variation within a single solstice period. This arises from the one degree spread in SZA and from weak attenuation by ozone in
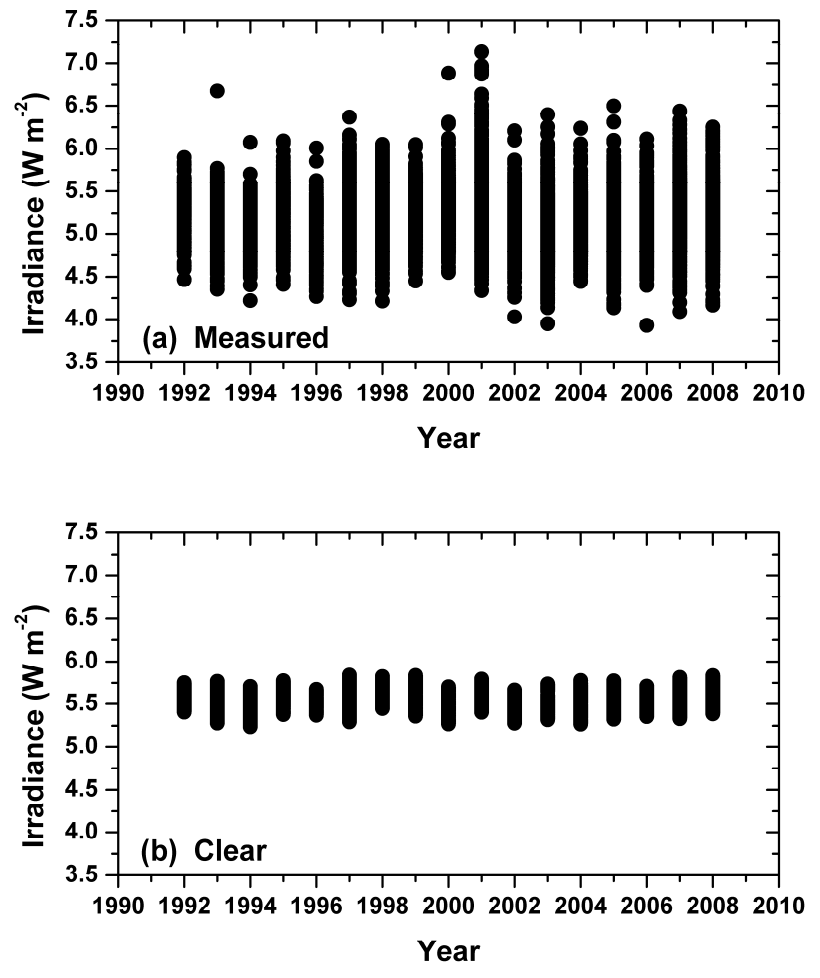

Fig. 1. The irradiance dataset for the wavelength band 320-340 nm covering 17 solstice periods, 1992-2008: (a) Measured values. (b) Computed clear-sky values.

the wavelength bands $320-340 \mathrm{~nm}$ and $400-600 \mathrm{~nm}$, while absorption by ozone is negligible between 340 and $400 \mathrm{~nm}$ (Molina and Molina, 1986; World Meteorological Organization, 1985). Column ozone amounts in early December are particularly variable owing to interannual differences in the dissipation of each year's springtime ozone reduction. Next, the variability in measured irradiance (Figs. 1a and 2a) during any one solstice period is substantially greater than in the corresponding clear-sky values. This is the expected result of varying cloudiness. Furthermore, measured irradiances in excess of the clear-sky values occur in both spectral bands, indicating that cloudiness can both decrease and increase ground-level irradiance. Finally, the percentage variability in irradiance at $400-600 \mathrm{~nm}$ is substantially greater than at 320-340 nm.

Table 1 presents some statistical properties of the dataset for all four wavelength bands, where the symbols $E_{\mathrm{MS}}$ and $E_{\mathrm{CL}}$ refer to the measured and clear-sky irradiances, respectively. Note in particular the fractional variability, defined as the ratio of the standard deviation to the mean irradiance, $\sigma\left(E_{\mathrm{MS}}\right) /<E_{\mathrm{MS}}>$ and $\sigma\left(E_{\mathrm{CL}}\right) /<E_{\mathrm{CL}}>$, based on all data points for each wavelength band. For the clear-sky calculations $\sigma\left(E_{\mathrm{CL}}\right) /<E_{\mathrm{CL}}>$ is greatest at the shortest wavelength where absorption by ozone is relatively important, and it remains essentially constant at longer wavelengths reflecting 
Table 1. Statistical characteristics of the irradiance dataset ${ }^{\mathrm{a}}$.

\begin{tabular}{lrrrr}
\hline $\begin{array}{l}\text { Wavelength } \\
\text { band } \\
(\mathrm{nm})\end{array}$ & $\begin{array}{r}\text { Mean measured } \\
\text { irradiance: }<E_{\mathrm{MS}}> \\
\left(\mathrm{W} \mathrm{m}^{-2}\right)\end{array}$ & $\begin{array}{r}\text { Fractional } \\
\text { variability }:\end{array}$ & $\begin{array}{r}\text { Mean clear-sky } \\
\text { irradiance: }<E_{\mathrm{CL}}> \\
\left(\mathrm{W} \mathrm{m}^{-2}\right)\end{array}$ & $\begin{array}{r}\text { Fractional } \\
\text { variability }{ }^{\mathrm{b}} \text { : }\end{array}$ \\
\hline $320-340$ & 5.30 & 0.050 & 5.62 & 0.022 \\
$340-360$ & 6.53 & 0.056 & 6.93 & 0.017 \\
$360-400$ & 15.37 & 0.068 & 16.39 & 0.016 \\
$400-600$ & 133.8 & 0.093 & 141.5 & 0.016 \\
\hline
\end{tabular}

${ }^{a}$ Based on 37173 data points at each wavelength.

${ }^{\mathrm{b}}$ Ratio of standard deviation to the mean irradiance.
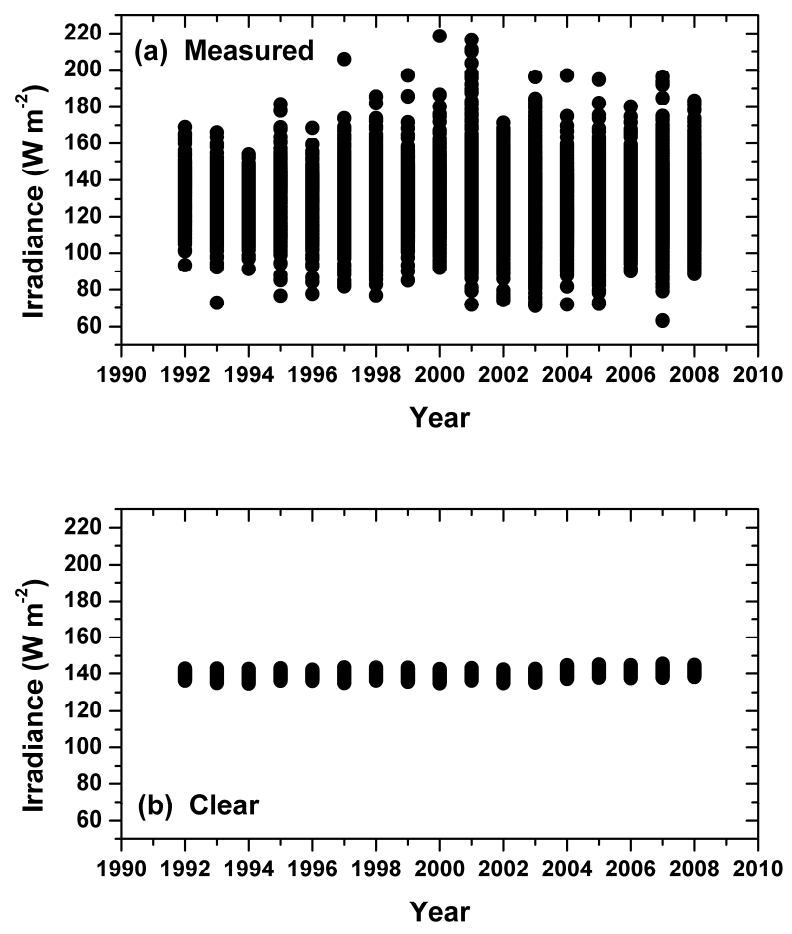

Fig. 2. The irradiance dataset for the wavelength band $400-600 \mathrm{~nm}$ covering 17 solstice periods, 1992-2008: (a) Measured values. (b) Computed clear-sky values.

the small variation in SZA. The measured irradiances show a very different pattern. Here the fractional variability represented by $\sigma\left(E_{\mathrm{MS}}\right) /<E_{\mathrm{MS}}>$ increases systematically with increasing wavelength, reaching almost six times the clearsky value in the $400-600 \mathrm{~nm}$ wavelength band.

To characterize the influence of cloudiness on surface irradiance it is useful to define a quantity that is independent of both the ozone amount and the SZA. The ratio of measured to clear-sky irradiance serves this purpose:

$R(\lambda)=E_{\mathrm{MS}}(\lambda, \theta) / E_{\mathrm{CL}}(\lambda, \theta, \Omega)$ where $\lambda$ labels a wavelength band, and the calculation in the denominator uses the SZA $\theta$ appropriate to the measurement and a column ozone value $\Omega$ derived from the spectroradiometer data.

In an ideal circumstance, the value of the irradiance ratio would depend only on the influence of clouds and any other form of atmospheric opacity that affects the measurements but that is not included in the clear-sky calculations. In practice, however, several factors related to instrument performance can influence the measured irradiance. A detailed uncertainty budget for irradiance at three wavelengths, 310, 400 and $600 \mathrm{~nm}$, appears in Bernhard et al. (2004). A substantial source of uncertainty, $2.1 \%(600 \mathrm{~nm})$ to $2.7 \%(310 \mathrm{~nm})$, centers on absolute calibration and stability. An additional uncertainty associated with the cosine response of the diffuser plate depends on details of the prevailing clouds, and for $\mathrm{SZA}=70^{\circ}$ this can be as large as $1.0 \%(310 \mathrm{~nm})$ to $2.8 \%$ $(600 \mathrm{~nm})$ when the sky condition is unknown. The geophysical variations of interest in Section 4 of this paper can be of the same order as the above uncertainties. Fortunately, errors that are independent of time do not impact the primary conclusions. However, uncorrected drifts or discontinuities could be misconstrued as a linear trend over time, and the statistical analyses in Sect. 4 must acknowledge this possibility.

Figure $3 \mathrm{a}-\mathrm{b}$ presents irradiance ratios measured in the $320-340 \mathrm{~nm}$ and 400-600 nm bands for the December 2001 solstice period, where the horizontal scale is day number measured from the start of the period. Figure $4 \mathrm{a}-\mathrm{b}$ is the analogous plot for the December 2007 solstice. These figures illustrate the varying influence of cloud cover among different solstice periods, with the earlier time (Fig. 3) exhibiting less cloudiness than the latter (Fig. 4). Clouds over the South Pole tend to be thin, often covering only a fraction of the sky, and their rapid variability leads to fluctuations in surface irradiance over time scales that are very short compared to a solstice period. Irradiances both less than and greater than the clear sky value can occur during the span of several hours. A comparison of Fig. 3a with $b$ or of Fig. 4a with $b$ shows that fluctuations observed in different wavelength bands are highly correlated, but they differ in magnitude. When the 

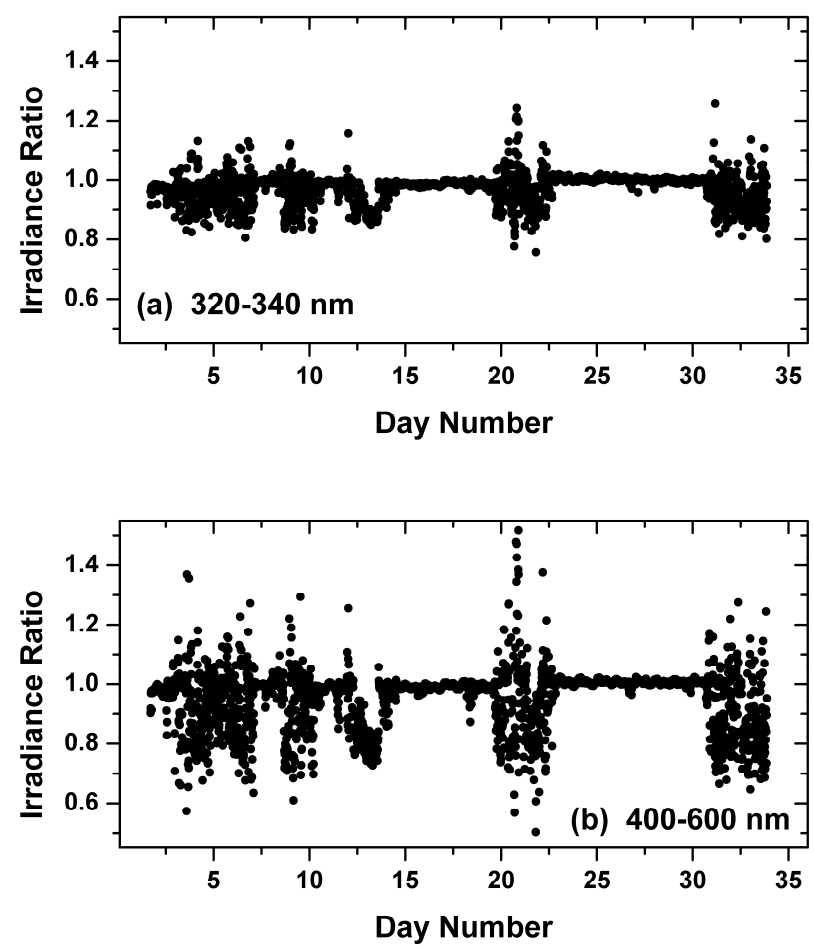

Fig. 3. Irradiance ratios for the solstice period December 2001 to January 2002, a relatively clear period: (a) 320-340 nm wavelength band. (b) $400-600 \mathrm{~nm}$ wavelength band. Day number 1 is 7 December 2001.

irradiance ratios deviate from 1.0, the deviation for the 400$600 \mathrm{~nm}$ band is always greater, either positive or negative, than that at $320-340 \mathrm{~nm}$.

The box plots for $320-340 \mathrm{~nm}$ and $400-600 \mathrm{~nm}$ in Fig. 5 further illustrate the wavelength dependence associated with cloudiness. These summarize the statistical properties of the entire dataset where the upper and lower boxes, respectively, identify the second and third quartiles of the measurements, and the horizontal line separating these boxes is the median. The vertical line segments with error bars similarly define the first and fourth quartiles, while the x-symbols denote outliers. The small squares at $0.94-0.95$ for each wavelength are the mean irradiance ratios. Although these are virtually the same at both wavelengths shown, as well as for the $340-$ $360 \mathrm{~nm}$ and $360-400 \mathrm{~nm}$ bands (not shown), the variability increases substantially with wavelength. Furthermore, irradiance ratios in excess of 1.0 are far more common in the $400-600 \mathrm{~nm}$ band than at $320-340 \mathrm{~nm}$.

To further define the spectral character of the attenuations and enhancements provided by clouds, Fig. 6 plots the irradiance ratios at $320-340 \mathrm{~nm}$ versus those at 400 $600 \mathrm{~nm}$ for the entire database. The line with a slope of 1.0 illustrates the case of no wavelength dependence and obviously deviates from the measurements which form an envelope of much smaller slope. A least squares fit
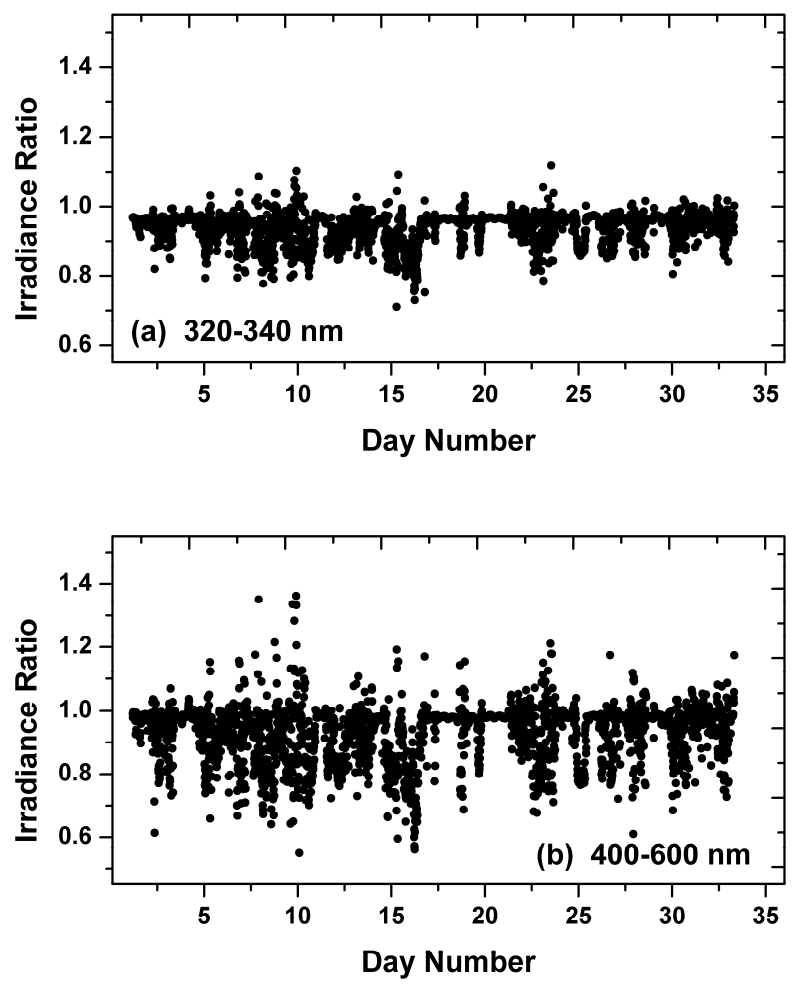

Fig. 4. Irradiance ratios for the solstice period December 2007 to January 2008, a relatively cloudy period: (a) $320-340 \mathrm{~nm}$ wavelength band. (b) 400-600 nm wavelength band. Day number 1 is 7 December 2007.

to the individual points has the form $R(320-340 \mathrm{~nm})=$ $(0.565 \pm 0.003)+(0.402 \pm 0.003) R(400-600 \mathrm{~nm})$ where the error bars are two standard errors, and the regression explains $67.6 \%$ of the variance. This shows quantitatively that the $320-340 \mathrm{~nm}$ signal has much less variation in response to changing cloudiness than does that for $400-600 \mathrm{~nm}$.

Figure $7 \mathrm{a}-\mathrm{b}$, for $320-340 \mathrm{~nm}$ and $400-600 \mathrm{~nm}$, defines the multi-year behavior of the irradiance ratios as well as an index of the variability within each solstice period. The dots depict the mean irradiance ratio for each solstice period, while the error bars are plus and minus one standard deviation. The different degree of variability in the two wavelength bands is apparent from the widths of the error bars.

When fractional cloud cover is present, the angular distribution of downward diffuse radiance incident on the sensor can vary with polar and azimuthal angle in a complicated manner that can not be modeled rigorously (Bernhard et al., 2004). This creates uncertainties when applying wavelengthdependent corrections for an imperfect cosine response to the measured irradiances, which may be entirely diffuse or a sum of direct and diffuse components, depending on the sky condition. Given this complexity, one can ask if the wavelength dependence in Figs. 6 and 7 might arise from uncorrected cosine response errors. 
One approach to addressing this is to assume that the "true" irradiance ratios are independent of wavelength, $R(320-340 \mathrm{~nm})=R(400-600 \mathrm{~nm})$, and that the wavelength dependence derived from Fig. 6 is an artifact of uncorrected errors. How large must these errors be in order to produce the regression equation derived above?

If $R(400-600 \mathrm{~nm})=1.2$, corresponding to a partly cloudy sky with the solar disk not obscured, then the regressionbased value of $R(320-340 \mathrm{~nm})$ is $12.7 \%$ smaller than the "true" value (1.0474 versus 1.2). If $R(400-600 \mathrm{~nm})=0.6$, corresponding to an obscured solar disk and a sky likely $100 \%$ cloud covered, then the measured value of $R\left(320_{-}\right.$ $340 \mathrm{~nm})$ is $31.9 \%$ larger than the "true" value $(0.7912$ versus 0.6). The result for the case of $R(400-600 \mathrm{~nm})=0.6$ is especially important since the diffuse irradiance should be nearly isotropic over the hemisphere here, minimizing the uncertainty in the cosine correction. Although the above argument is not definitive, these differences seem unreasonably large to arise entirely from uncorrected cosine errors. In any event, Fig. 11, to be discussed later, shows that a purely model-based calculation produces a wavelength dependence remarkably close to that deduced from the measurements. This approach provides a convincing argument that the empirical results are valid.

Several features of the dataset require an explanation grounded in a theoretical understanding of the processes at work. These are (1) irradiances larger than the clear-sky values are frequent occurrences, and (2) the variability in irradiance associated with cloudiness is greater in the visible than in the UV-A. The following section addresses these issues based on physical reasoning combined with a set of radiative transfer calculations that incorporate a simplified treatment of fractional cloudiness. The final topic of the paper involves interannual variability in cloudiness. The goal here is to determine whether the variations shown in Fig. 7 are seemingly random or whether there are systematic trends or possible links to solar activity.

\section{Irradiances under partly cloudy skies: a theoretical analysis}

Figure 6 shows that irradiances in excess of the clear sky value are common, particularly at $400-600 \mathrm{~nm}$. A series of one-dimensional radiative transfer calculations based on the simplified cloud cover formulation first presented by Frederick and Erlick (1995) provides an explanation for this behavior as well as for the wavelength dependence that appears when clouds are present. A number of previous studies have examined the wavelength dependent attenuation provided by clouds from both the empirical and theoretical standpoints (Seckmeyer et al., 1996; Frederick and Erlick, 1997; Kylling et al., 1997; Lindfors and Arola, 2008). The present work focuses specifically on effects associated with fractional cloud cover as opposed to a uniform cloud layer.

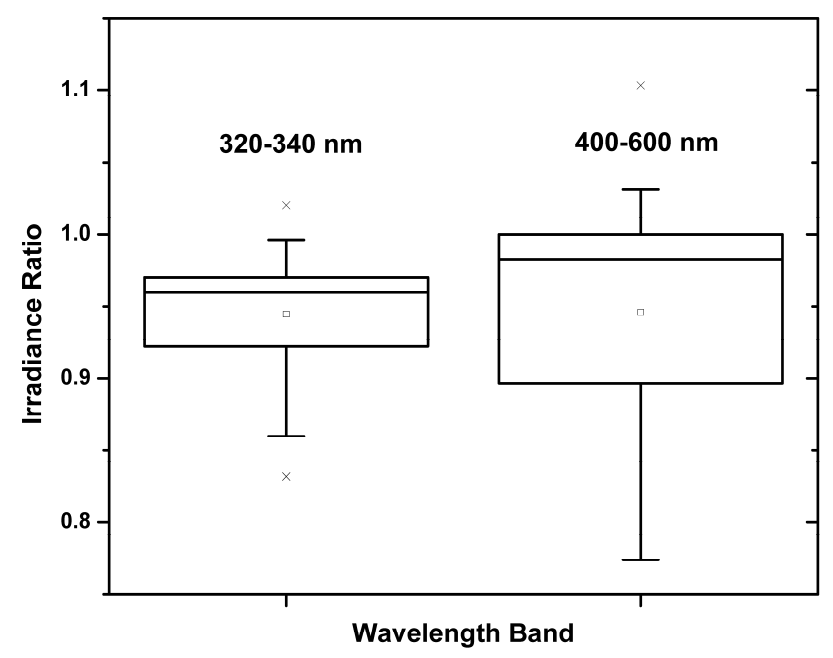

Fig. 5. Box plots of all irradiance ratios for the $320-340 \mathrm{~nm}$ and 400-600 nm wavelength bands. The upper and lower boxes, respectively, for each wavelength define the second and third quartiles of the measurements. The upper and lower vertical lines, respectively, define the first and fourth quartiles. Small squares in the third quartile for each wavelength represent means, and the x-symbols are outliers.

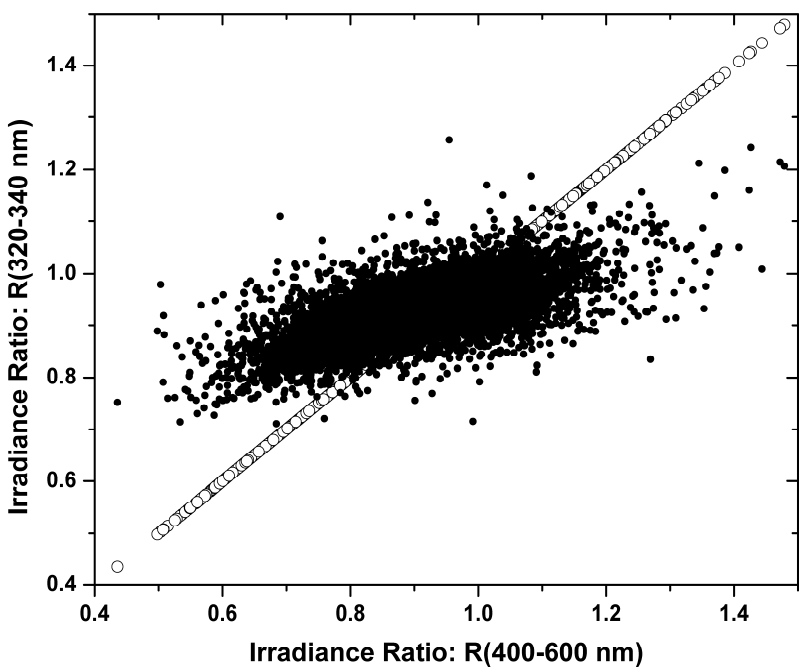

Fig. 6. Dark circles denote measured irradiance ratios for 320 $340 \mathrm{~nm}$ plotted against those for $400-600 \mathrm{~nm}$, showing the wavelength dependence in the attenuation or enhancement in solar irradiance associated with South Polar clouds. The straight line and squares indicate a hypothetical case of no wavelength dependence.

The one-dimensional radiative transfer calculation breaks the total solar radiation field at each wavelength step into downward direct, downward diffuse and upward diffuse contributions, where the diffuse, scattered radiances have components that vary linearly with the cosine of the polar angle as in the Eddington approximation (Shettle and Weinmann, 

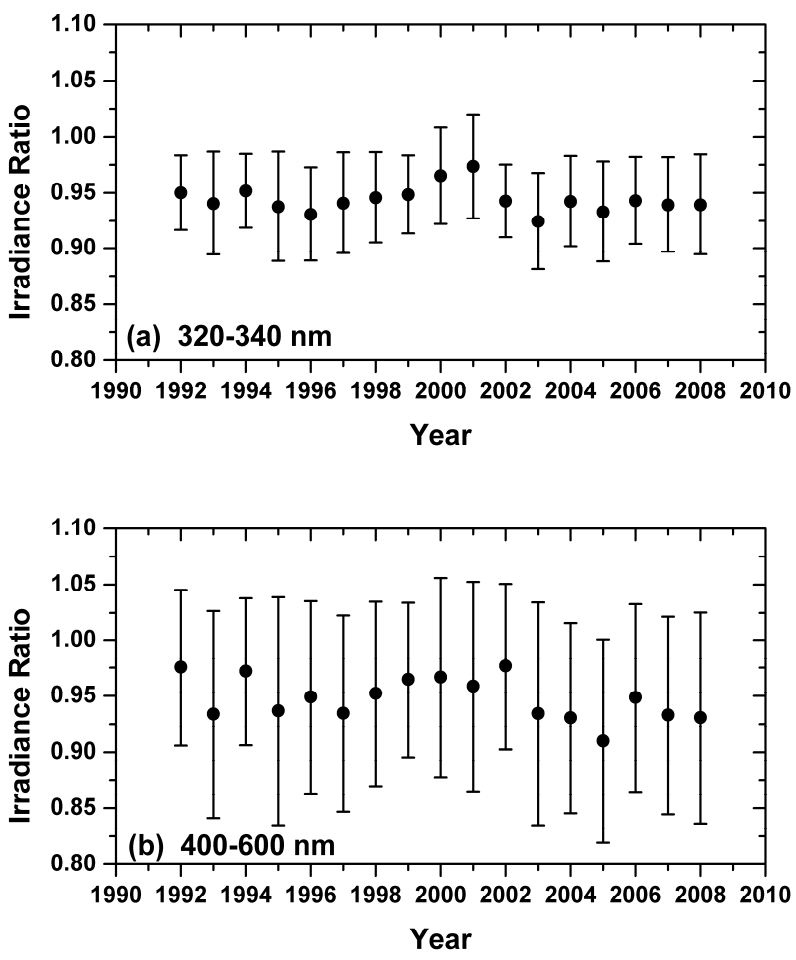

Fig. 7. Statistical summary of irradiance ratios for each solstice period: dots are mean irradiance ratios. Error bars are plus and minus one standard deviation and indicate the variability associated with cloudiness. (a) 320-340 nm wavelength band. (b) 400-600 nm wavelength band.

1970). The problem is then cast in the form of two radiative transfer equations, one for downward diffuse and the other for upward diffuse irradiance, where the direct irradiance is obtained via Beer's Law. The calculation treats absorption by ozone using a specified vertical profile, Rayleigh scattering based on a polar density profile and reflection from a lower boundary.

The handling of fractional cloudiness is a unique aspect of the calculation. Note that any attempt to incorporate the effects of fractional cloudiness into a one-dimensional calculation must rest on major assumptions since the true radiative transfer problem is inherently three-dimensional. The model treats a cloud as a diffusing surface placed at a specified altitude, where a fraction $f_{c}$ of the upper hemisphere is covered by clouds of albedo $A_{c}$. For ease of discussion we adopt the same cloud albedo for both direct and diffuse incident radiation, although this is not true in general. The following quantities are computed as part of the solution to the radiative transfer equation: $E_{a}(\mathrm{dn})$ is the downward diffuse irradiance incident on the cloud top from above, $E_{a}$ (dir) is the downward direct irradiance incident on the cloud top from above and $E_{b}$ (up) is the upward diffuse irradiance incident on the cloud base from below. Given these, the cloud- treatment computes the downward diffuse irradiance at the cloud base, labeled as $E_{b}(\mathrm{dn})$, and the upward diffuse irradiance at the cloud top, labeled as $E_{a}$ (up).

When no absorption occurs inside the cloud, conservation of energy requires the following conditions to be true:

$$
\begin{aligned}
E_{b}(\mathrm{dn})= & f_{c}\left(1-A_{c}\right)\left[E_{a}(\mathrm{dir})+E_{a}(\mathrm{dn})\right]+f_{c} A_{c}\left[E_{b}(\mathrm{up})\right] \\
& +\left(1-f_{c}\right)\left[E_{a}(\mathrm{dn})\right] \\
E_{a}(\mathrm{up})= & f_{c}\left(1-A_{c}\right)\left[E_{b}(\mathrm{up})\right]+f_{c} A_{c}\left[E_{a}(\mathrm{dir})+E_{a}(\mathrm{dn})\right] \\
& +\left(1-f_{c}\right)\left[E_{b}(\mathrm{up})\right] \\
E_{b}(\mathrm{dir})= & \left(1-f_{c}\right)\left[E_{a}(\mathrm{dir})\right]
\end{aligned}
$$

The expressions for the diffuse irradiances, $E_{b}(\mathrm{dn})$ and $E_{a}$ (up), require no further modification. However, the expression for the direct irradiance that comes though the clear fraction of the sky is problematic. Averaged over a substantial horizontal area, the above three equations must be true to ensure energy conservation. But at any specific location at the ground, the solar disk is likely to be totally visible or totally obscured by clouds. It is as if $f_{c}$ in Eq. (4) takes on only the values $f_{c}=0$ or $f_{c}=1$ regardless of the actual value of fractional cloudiness used in the calculation of diffuse irradiances.

The calculation allows the solar disk to be either entirely visible, which leads to irradiances in excess of the clearsky value when clouds are present, or entirely obscured by clouds, which leads to irradiances less than the clear sky value. The computed diffuse irradiance can be interpreted as an average over the horizontal area to which the fractional cloud cover refers, while the computed direct irradiance refers to the specific location of the sensor.

Over the South Pole, the surface albedo is horizontally homogeneous, which is consistent with a one-dimensional calculation. Also, the clouds, particularly when fractional cloudiness prevails, are likely to be thin, so that complications associated with the sides of clouds are minimized. Still, the calculation seeks to capture the physics of a threedimensional situation in a one-dimensional model. While the calculations illustrate the mechanisms at work, one should not use the radiative transfer model to infer properties of the clouds from the measurements

To see how irradiances larger than the clear-sky values occur, consider a sky that is partly covered by clouds, with $f_{c}$ and $A_{c}$ as defined above. Assume that, as viewed from the location of a ground-based sensor, the solar disk is in the clear portion of the sky. The irradiance that strikes the sensor consists of a direct component, which is identical to what would exist under a clear sky, and a diffuse component that represents contributions from both the clear and cloudy portions of the sky.

Downward solar irradiance incident on the cloud tops consists of both a direct and a diffuse component, where scattering above the clouds determines their relative proportions. A 
fraction $1-A_{c}$ of the incident diffuse radiation is transmitted through the cloud. For $A_{c}>0$ this mechanism always acts to decrease the irradiance that ultimately reaches a groundbased sensor. Similarly, the direct component of solar irradiance incident on the cloud tops is partially reflected back upward and partially transmitted through the cloud, where a portion emerges as downward diffuse radiation. From this description, the direct solar beam influences the total irradiance received by the sensor in two ways. First, since the sun lies in the clear portion of the sky, the entire direct solar beam reaches the sensor. Second, a fraction of the direct solar irradiance is transmitted through the clouds, emerges as diffuse radiation, and some of this reaches the sensor. In some circumstances, this second contribution can increase the irradiance over what would exist under clear skies.

The backscattering of diffuse radiation incident on the cloud tops represents a loss of irradiance from the ground. But the transmission of direct radiation through the cloud, and its conversion to diffuse radiation in the process, represents a gain. If the gain in diffuse irradiance traceable to downward scattering of the direct solar beam in the clouds exceeds the loss from backscattering of diffuse radiation incident on the cloud tops, then the total irradiance measured at the ground will be greater than the value for clear skies.

Based on the above processes, measured irradiances in excess of the clear-sky value require the sky to be partly cloudy, with the solar disk in the clear portion of the sky as viewed from the sensor. This is a necessary, but not a sufficient, condition. As the ratio of direct to diffuse irradiance incident on the cloud top increases, the probability of an enhancement in ground-level irradiance over the clear-sky values also increases. This implies that irradiance ratios greater than 1.0 should be more common at the longer wavelengths observed. Figure 5 shows this to be the case. Should the solar disk become obscured by cloudiness as seen from the sensor, the direct beam is lost, and the irradiance will drop to levels less than those for a clear sky.

Figure $8 \mathrm{a}-\mathrm{b}$, for the wavelength bands $320-340 \mathrm{~nm}$ and 400-600 nm, illustrates the processes at work. Each panel presents the irradiance ratio computed as a function of fractional cloudiness $f_{c}$, where the solar disk is in the clear portion of the sky. The ground albedo is set to $A_{G}=0$ in both cases so as to highlight the mechanism discussed above. The case $f_{c}=1$ corresponds to complete cloud cover except for a small break that coincides with the line of sight to the sun as viewed from the sensor. Each panel includes results for three cloud albedos, $A_{c}=0.5,0.7$ and 0.9 .

A large ratio of direct to diffuse irradiance at the cloud top promotes surface irradiances greater than the clear-sky value, and this ratio is wavelength dependent as a simple result of Rayleigh scattering. This wavelength dependent effect is evident in comparing Fig. 8a and b, where irradiance ratios larger than 1.0 arise most readily in the $400-600 \mathrm{~nm}$ wavelength band. Figure 8 a for 320-340 nm shows that when the cloud albedo is $A_{c}=0.5$ a small enhancement exists for all
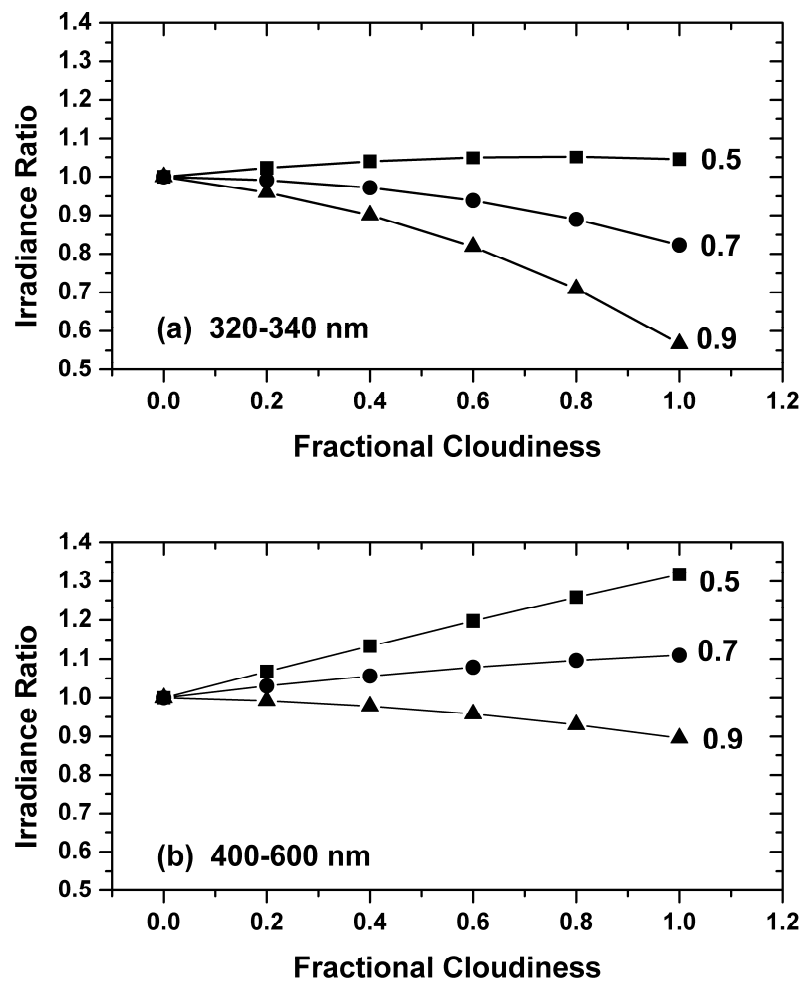

Fig. 8. Computed irradiance ratios as functions of fractional cloudiness for cloud albedos of $A_{c}=0.5,0.7$ and 0.9. The solar disk is not obscured by clouds, and the ground albedo is $A_{G}=0.0$. (a) 320 $340 \mathrm{~nm}$ wavelength band. (b) $400-600 \mathrm{~nm}$ wavelength band.

values of fractional cloudiness. When $A_{c}=0.7$ or 0.9 transmission through the cloud is restricted, and the surface irradiance is less than the clear-sky result. In the 400-600 nm band (Fig. 8b) the diffuse irradiance incident on the cloud top is relatively small compared to the direct component. The mechanisms discussed above now lead to an increase in ground-level irradiance with fractional cloudiness for cloud albedos of 0.5 and 0.7 , where all values exceed the clear-sky irradiance. When the cloud albedo reaches 0.9 , the radiation that emerges downward from the cloud base is always less than would exist under clear skies, and the effect is to reduce the irradiance received at the ground.

A comparison of Fig. 8a and b for a cloud albedo of $A_{c}=$ 0.7 reveals an unexpected and interesting result. As fractional cloud cover increases, the ground-level irradiance for $400-600 \mathrm{~nm}$ increases, while that at 320-340 $\mathrm{nm}$ decreases. This demonstrates that even the sign of the change in irradiance for a specified change in cloudiness can depend on wavelength and details of the prevailing sky cover.

The above arguments considered only the direct and diffuse radiation incident on cloud tops. Another important mechanism for enhancing surface irradiance centers on the albedo $A_{G}$ of the lower boundary. When $A_{G}$ is large, as is the case at the South Pole, multiple reflections between 

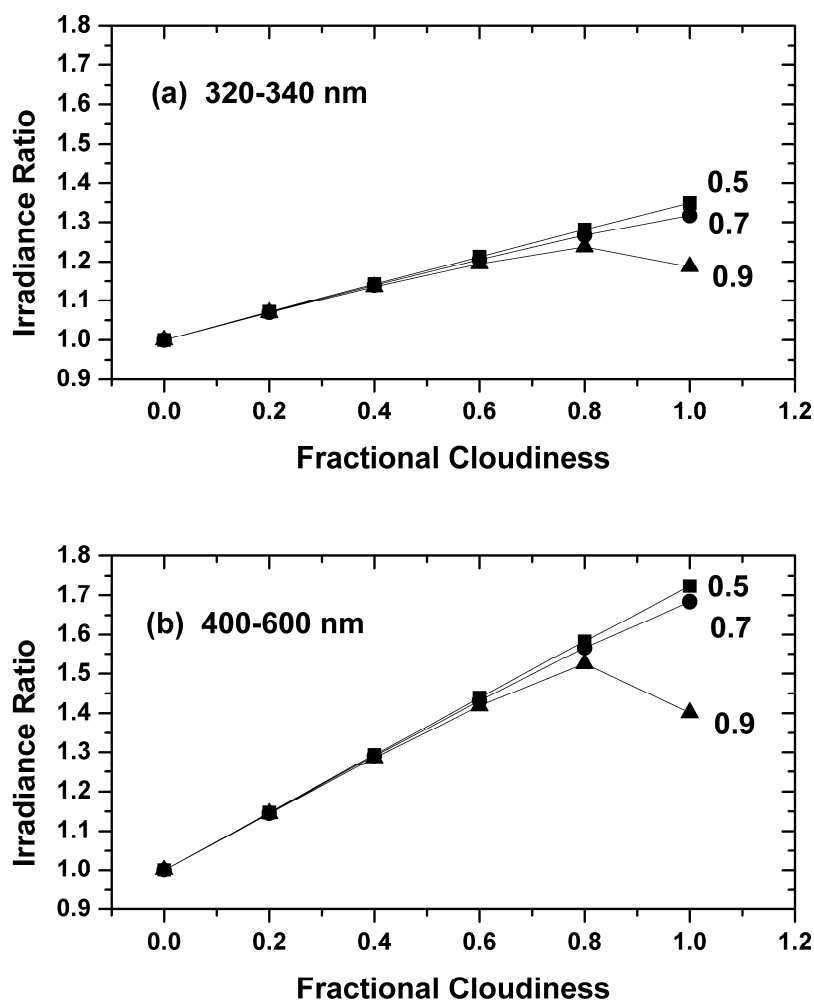

Fig. 9. Computed irradiance ratios as functions of fractional cloudiness for cloud albedos of $A_{c}=0.5,0.7$ and 0.9. The solar disk is not obscured by clouds, and the ground albedo is $A_{G}=0.98$. (a) 320 $340 \mathrm{~nm}$ wavelength band. (b) $400-600 \mathrm{~nm}$ wavelength band.

the ground and cloud enhance the irradiance that reaches a sensor. Under conditions of fractional cloud cover, the solar disk may be visible as viewed from the ground-based sensor; however, the clouds will hide the disk as seen from other nearby locations. If fractional cloudiness $f_{c}$ is small, a relatively large direct irradiance reaches the ground when averaged over the area of interest, and multiple reflections occur between the ground and cloud base. However, the small fractional cloud cover limits the magnitude of the resulting irradiance enhancement. As $f_{c}$ increases, a larger cloud-base area backscatters upwelling radiation, but the increased areaaveraged blockage of the solar disk acts to limit the amount of energy that penetrates beneath the cloud and is available for this reflection. The result is that the irradiance observed by a sensor increases with $f_{c}$ up to some maximum, depending on the cloud albedo, and then can decline with further increases in fractional cloudiness.

Figure $9 \mathrm{a}-\mathrm{b}$ is analogous to Fig. 8a-b except that the ground albedo is $A_{G}=0.98$, typical of the Antarctic surface (Grenfell et al., 1994). Even under clear skies this large albedo produces significantly enhanced irradiances relative to the case $A_{G}=0.0$. For the wavelength band 400 $600 \mathrm{~nm}$ the increase is $8.2 \%$, while at $320-340 \mathrm{~nm}$ the corresponding number is $38.5 \%$. The larger clear-sky percent- age increase at the shorter wavelengths arises from stronger Rayleigh backscattering of radiation previously reflected upward at the lower boundary.

The irradiance ratios in Fig. 9a-b display the behavior expected from the physical reasoning presented above. When fractional cloudiness exceeds 0.8 for the highest cloud albedo $\left(A_{c}=0.9\right)$ the solar energy beneath the cloud is severely limited and increases from multiple reflections between the ground and cloud base are inhibited. In this case, irradiance declines with further increases in $f_{c}$. Finally, Fig. 10a-b, for the wavelength bands $320-340 \mathrm{~nm}$ and $400-600 \mathrm{~nm}$, illustrates the effect of the solar disk being obscured by clouds. The case $f_{c}=0$ here refers to a cloud-free sky except for a small disk of albedo $A_{c}$ that coincides with the location of the sun. The three curves in each panel depict irradiance ratios for cloud albedos of $A_{c}=0.5,0.7$ and 0.9 , respectively, and the surface albedo is $A_{G}=0.98$ in all cases. Note the wavelength dependence in the attenuation, where the effect of clouds for $400-600 \mathrm{~nm}$ is usually exaggerated relative to that at $320-340 \mathrm{~nm}$.

Figures 9 and 10 demonstrate that radiative transfer theory applied to partly-cloudy skies produces the wavelengthdependent attenuation and enhancement observed at the South Pole. Figure 11, based entirely on radiative transfer calculations, presents $R(320-340 \mathrm{~nm})$ plotted against $R\left(400_{-}\right.$ $600 \mathrm{~nm})$. The results are very similar to the analogous empirical plot in Fig. 6. A linear fit to the computed curve gives $R(320-340 \mathrm{~nm})=(0.589 \pm 0.011)+(0.430 \pm 0.010) R(400$ $600 \mathrm{~nm}$ ), where the slope is only $7 \%$ larger than the value derived from Fig. 6 .

\section{Long-term behavior of the irradiance ratios}

This section considers relationships between the irradiance ratios and indices of interannual variability. The goal is to determine if the solar irradiance, as depicted in Fig. 7, contains systematic behavior over the time period of observation or if the year-to-year variation is random. Mean irradiance ratios for any solstice period characterize the net influence of clouds, and all other forms of variation not included in the clear-sky calculations, on solar irradiance at the ground. The analysis below considers two forms of long-term variability: (1) linear trends in time and (2) links to the solar cycle. The calendar year that contains December provides the measure of time, while we characterize the solar cycle by the mean $10.7 \mathrm{~cm}$ solar radio flux $\left(F_{10.7}\right)$ adjusted to 1.0 Astronomical Unit for each solstice period (NOAA National Geophysical Data Center, 2010). Figure 12 presents this indicator of solar activity for the period studied. Note that the value of $F_{10.7}$ for the 2001 solstice period is unusually large.

To check for systematic long-term behavior in the dataset, Table 2 presents linear correlation coefficients $(r)$ between the mean irradiance ratios in each wavelength band and the year, as well as the probabilities $(P)$ that the correlations 

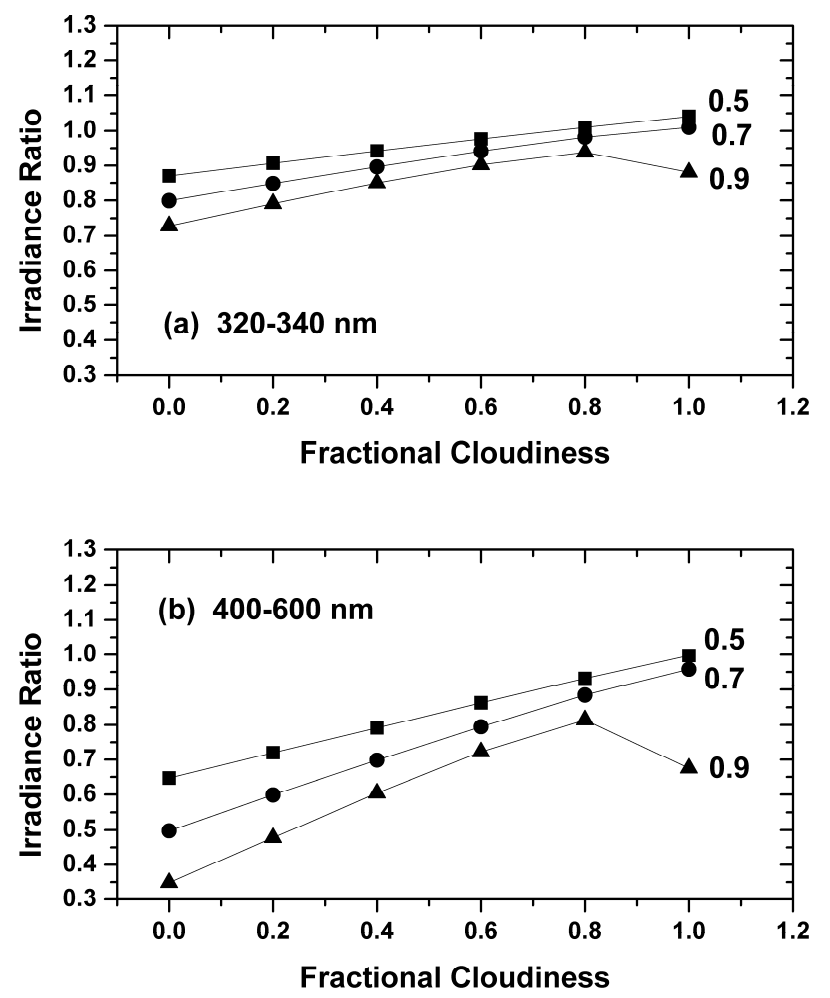

Fig. 10. Computed irradiance ratios as functions of fractional cloudiness for cloud albedos of $A_{c}=0.5,0.7$ and 0.9 . The solar disk is obscured by clouds, and the ground albedo is $A_{G}=0.98$. (a) $320-340 \mathrm{~nm}$ wavelength band. (b) 400-600 nm wavelength band.

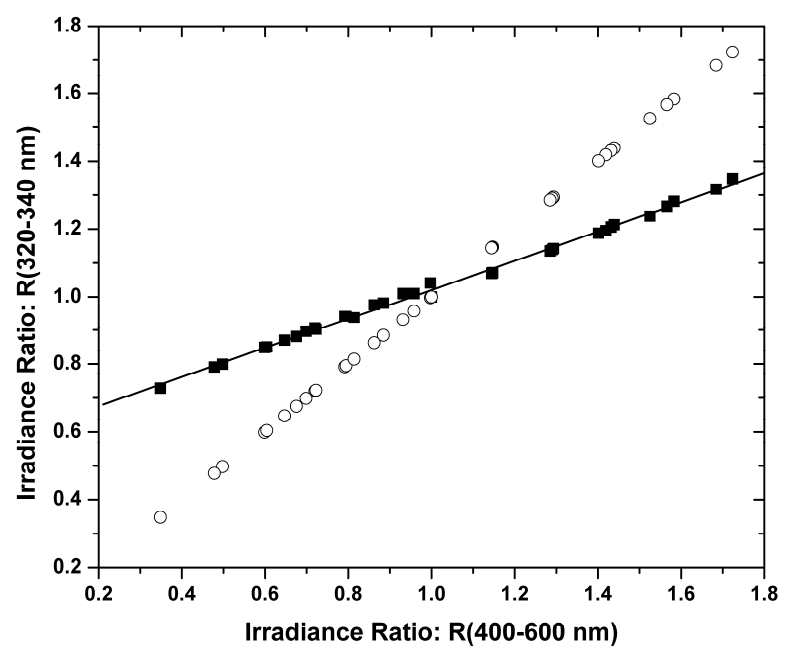

Fig. 11. Computed irradiance ratios for 320-340 nm plotted against those for $400-600 \mathrm{~nm}$, showing the wavelength dependence in the attenuation or enhancement in solar irradiance associated with clouds as produced by theory. Open circles define the case of no wavelength dependence. The solid line is a fit to radiative transfer calculations indicated by squares.

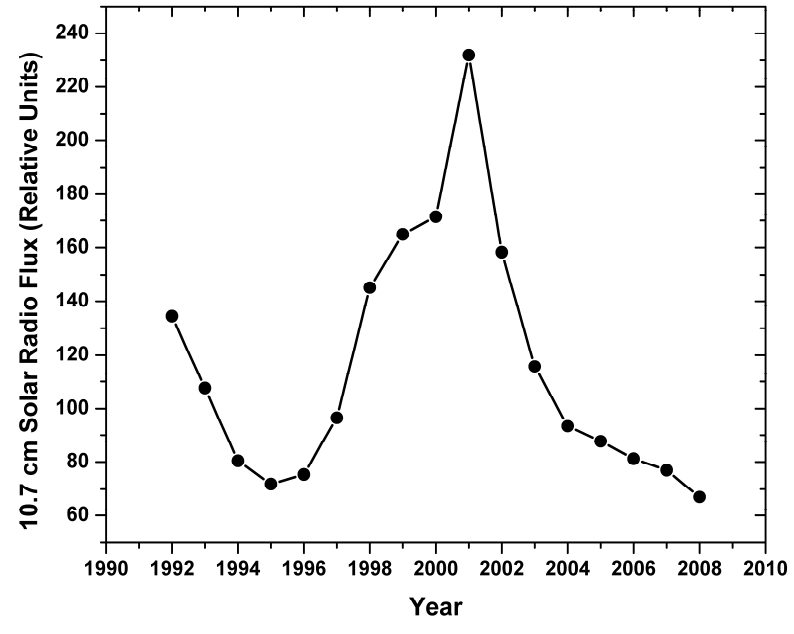

Fig. 12. Solar $10.7 \mathrm{~cm}$ radio flux in relative units: points are means of daily measured values for each 30-35 day solstice period.

arise by chance. For future reference, the correlation between $F_{10.7}$ and year appears as well. Based on the standard criterion of $P<0.05$, the irradiance ratios and the $10.7 \mathrm{~cm}$ flux contain no significant linear trends over time, although some indication of a downward trend exists $(P=0.08)$ in the $400-600 \mathrm{~nm}$ irradiance ratio. If we interpret the behavior as a linear change over time, it corresponds to a decrease of approximately $1.5 \pm 1.6 \%$ per decade, where the $95 \%$ confidence interval encompasses zero.

The hint of a downward trend in the visible band merits further attention. A systematic change in cloudiness would preferentially influence the $400-600 \mathrm{~nm}$ irradiance owing to the enhanced sensitivity of the signal at longer wavelengths. Furthermore, clouds over the South Pole induce erratic variability into the irradiance (Figs. 3 and 4), so that a longterm trend in cloudiness should appear in the irradiance ratios and their standard deviations. Specifically, unusually cloudy solstice periods would exhibit both small mean irradiance ratios and large standard deviations. However, statistical analysis shows no significant trend in the standard deviation for $400-600 \mathrm{~nm}$, the correlation with year being $r=0.31$ with $P=0.23$. The small correlations found for the other wavelength bands have even greater probabilities of arising by chance. Based on the information available, there is no compelling evidence of a trend in cloudiness over the South Pole for the time period studied. Statistically insignificant changes of the magnitude derived for 400-600 nm could arise by chance or from systematic errors in the dataset associated, for example, with replacement of instrument components.

Table 3 presents correlations between the mean irradiance ratios and the mean $10.7 \mathrm{~cm}$ solar radio flux, including probabilities that the relationships arise by chance. In view of the unusually large $F_{10.7}$-value for 2001, separate results appear 
based on all 17 solstice periods and on only 16 periods, with 2001 omitted. We regard the former case to be the primary result, but want to ensure that removal of one particular year does not alter the general conclusion. When all 17 years enter the calculation, significant positive correlations exist for each wavelength band, with $P<0.01$ in the ultraviolet and $P<0.05$ in the visible. With 2001 omitted, significant correlations remain at the $5 \%$ level of confidence. The absence of temporal trends in the irradiance ratios and in $F_{10.7}$ (Table 2) ensures that the results in Table 3 do not arise from an accidental confounding of linear behavior over time with solar activity. The conclusion from Table 3 is that the measured irradiances reaching the South Polar surface included a component that varied in phase with the solar cycle over the time period studied. This result applies both to the ultraviolet and visible regions.

The significant correlations in Table 3 motivated application of a regression model with the form:

$R(\lambda)=a_{0}+a_{1}\left[F_{10.7}-<F_{10.7}>\right] / 100+\varepsilon$

where $<F_{10.7}>$ is the average $10.7 \mathrm{~cm}$ radio flux for the entire period of observation, the coefficients $a_{0}$ and $a_{1}$ are to be determined, and $\varepsilon$ includes the unexplained variance. When all 17 solstice periods enter the regression $\left\langle F_{10.7}\right\rangle=115.3$, and when the 2001 period is omitted $\left.<F_{10.7}\right\rangle=108.1$. Table 4 lists the estimated coefficients $\left(a_{0}, a_{1}\right)$, their standard errors $\left(\alpha_{0}, \alpha_{1}\right)$, and the percent of variance explained by the model based on all 17 years. Table 5 presents analogous results with data for 2001 removed. A 100 unit change in $F_{10.7}$ leads to a best-estimate percentage change in irradiance ratio of $100 a_{1} / a_{0}$, which corresponds approximately to the difference between solar maximum and solar minimum. The $95 \%$ confidence interval spans the range $100\left(a_{1}-2 \alpha_{1}\right) / a_{0}$ to $100\left(a_{1}+2 \alpha_{1}\right) / a_{0}$. Table 6 presents these percentage changes.

When data from all years enter the regressions, the estimated irradiances for solar minimum are about $1.8 \%$ and $2.4 \%$ smaller than those at solar maximum for the wavelengths 320-400 nm (representing all three UV-A bands combined) and 400-600 $\mathrm{nm}$ respectively, with a larger error bar in the visible. The solar cycle remains, with a somewhat altered magnitude, when the regressions omit the 2001 solstice period. Here the estimated decrease from solar maximum to solar minimum is about $1.5 \%$ for $320-400 \mathrm{~nm}$ and $3.5 \%$ for $400-600 \mathrm{~nm}$, again with a larger error bar in the visible. We regard numbers based on all 17 solstice periods as the best estimates, but the persistence of a solar cycle dependence when data for 2001 are omitted indicates the robustness of the result. If these changes have a geophysical or solar origin, they must arise from (1) variations in the transmission of the South Polar atmosphere over the solar cycle during the time period studied, (2) variations in the extraterrestrial solar irradiance, which are implicit in the spectroradiometer measurements but are not included in the clearsky calculations, or (3) a combination of both mechanisms. Alternate interpretations are (1) an uncorrected error in the
Table 2. Correlation of mean irradiance ratios with year (based on 17 Solstice Periods, 1992 through 2008).

\begin{tabular}{lrr}
\hline Variable & $\begin{array}{r}\text { Correlation } \\
\text { with year }(r)\end{array}$ & $\begin{array}{r}\text { Probability by } \\
\text { chance }(P)\end{array}$ \\
\hline$R(320-340 \mathrm{~nm})$ & -0.16 & 0.54 \\
$R(340-360 \mathrm{~nm})$ & -0.20 & 0.45 \\
$R(360-400 \mathrm{~nm})$ & -0.20 & 0.45 \\
$R(400-600 \mathrm{~nm})$ & -0.43 & 0.08 \\
$F_{10.7}$ & -0.12 & 0.64 \\
\hline
\end{tabular}

measurements has an accidental correlation with the solar cycle or (2) the correlation is real in the mathematical sense but does not does arise from a causal physical link.

The data of Harder et al. (2009) and Haigh et al. (2010) also indicate an unexpected increase in the visible irradiance over the declining phase of the solar cycle from 2004 to 2007. The sign of the South Polar visible surface variation deduced here disagrees with these extraterrestrial observations. The regression based on 17 years of surface data produces a decrease in $400-600 \mathrm{~nm}$ irradiance of $2.4 \%$ from solar maximum to solar minimum, with an uncertainty range of $0.5-4.3 \%$. These percentages correspond to a decline in energy flux striking a horizontal surface at the ground of about $3.4 \mathrm{~W} \mathrm{~m}^{-2}$, with an uncertainty range of $0.7-6.1 \mathrm{~W} \mathrm{~m}^{-2}$ for a SZA near 67 degrees. Except perhaps for the very low end of the error range, these numbers are unacceptably large to interpret as being extraterrestrial. Even if one ignores the problem with the phase of the variation relative to the data of Harder et al. (2009) and Haigh et al. (2010), only numbers near the lower limit of the range are compatible with measured decreases in the Solar Constant of about $0.1 \%$, or $1.3 \mathrm{~W} \mathrm{~m}^{-2}$, from solar maximum to solar minimum (e.g. Cahalan et al, 2010).

One potential geophysical mechanism for changes in atmospheric transmission from one solstice season to the next involves cloudiness. The possibility that clouds are linked to solar activity has appeared in the literature, although the concept is controversial and conflicting results exist (Svensmark, 1998, 2007; Sloan and Wolfendale, 2008). As noted previously, clouds over the South Pole vary erratically. Hence, one expects differences in cloudiness between solstice seasons to appear both as a change in the mean value of $R(\lambda)$ as well as in its standard deviation. If the correlations between $R(\lambda)$ and $F_{10.7}$ arise from rapidly varying cloudiness whose details change from year-to-year over the solar cycle, then a correlation should also exist between the standard deviations and $F_{10.7}$. Table 7 presents these correlation coefficients. When all 17 years enter the regressions, there is clearly no link between the standard deviations and the solar cycle. When data for 2001 are omitted, the conclusion is less obvious, although with $P<0.05$ as the standard, no significant relationships appear. We conclude that interannual changes in the short- 
Table 3. Correlation of mean irradiance ratios $R(\lambda)$ with the $10.7 \mathrm{~cm}$ solar radio flux.

\begin{tabular}{lrrrr}
\hline Variable & $\begin{array}{r}\text { Correlation } \\
\text { with } F_{10.7}(r) \\
(17 \text { years })\end{array}$ & $\begin{array}{r}\text { Probability by } \\
\text { chance }(P) \\
(17 \text { years })\end{array}$ & $\begin{array}{r}\text { Correlation } \\
\text { with } F_{10.7}(r) \\
(\text { Omit 2001) }\end{array}$ & $\begin{array}{r}\text { Probability by } \\
\text { chance }(P) \\
(\text { Omit 2001) }\end{array}$ \\
\hline$R(320-340 \mathrm{~nm})$ & 0.74 & 0.001 & 0.54 & 0.030 \\
$R(340-360 \mathrm{~nm})$ & 0.72 & 0.001 & 0.54 & 0.030 \\
$R(360-400 \mathrm{~nm})$ & 0.62 & 0.008 & 0.54 & 0.032 \\
$R(400-600 \mathrm{~nm})$ & 0.55 & 0.021 & 0.61 & 0.012 \\
\hline
\end{tabular}

Table 4. Results from the regression model: $R(\lambda)=a_{0}+a_{1}\left[\left(F_{10.7}-<F_{10.7}>\right) / 100\right]+\varepsilon$ (applied to all 17 Solstice Periods).

\begin{tabular}{lrrrrr}
\hline $\begin{array}{l}\text { Wavelength } \\
\text { band (nm) }\end{array}$ & $a_{0}$ & $\alpha_{0}^{\mathrm{a}}$ & $a_{1}$ & $\alpha_{1}^{*}$ & $\begin{array}{r}\% \text { Variance } \\
\text { explained }\end{array}$ \\
\hline $320-340$ & 0.944 & 0.00201 & 0.0190 & 0.00451 & 54.1 \\
$340-360$ & 0.942 & 0.00174 & 0.0158 & 0.00391 & 52.3 \\
$360-400$ & 0.938 & 0.00220 & 0.0151 & 0.00494 & 38.4 \\
$400-600$ & 0.948 & 0.00399 & 0.0231 & 0.00896 & 30.6 \\
\hline
\end{tabular}

${ }^{*} \alpha_{i}=$ standard error of coefficient $a_{i}, i=1,2$.

Table 5. Results from the regression model: $R(\lambda)=a_{0}+a_{1}\left[\left(F_{10.7}-<F_{10.7}>\right) / 100\right]+\varepsilon$ (applied to 16 Solstice Periods, Omitting Data for 2001).

\begin{tabular}{lrrrrr}
\hline $\begin{array}{l}\text { Wavelength } \\
\text { band (nm) }\end{array}$ & $a_{0}$ & $\alpha_{0}^{*}$ & $a_{1}$ & $\alpha_{1}^{*}$ & $\begin{array}{r}\% \text { Variance } \\
\text { explained }\end{array}$ \\
\hline $320-340$ & 0.942 & 0.00203 & 0.0142 & 0.00587 & 29.4 \\
$340-360$ & 0.940 & 0.00179 & 0.0125 & 0.00517 & 29.3 \\
$360-400$ & 0.937 & 0.00234 & 0.0161 & 0.00677 & 28.8 \\
$400-600$ & 0.947 & 0.00400 & 0.0333 & 0.0116 & 37.2 \\
\hline
\end{tabular}

${ }^{*} \alpha_{i}=$ standard error of coefficient $a_{i}, i=1,2$.

term variability of South Polar clouds are not the origin of the correlations in Tables 4 and 5.

Variability in the extraterrestrial solar irradiance provides an obvious explanation for the correlations in Table 3, although the estimated magnitudes are not necessarily consistent with current understanding. The space-based spectral irradiance measurements of Harder et al. (2009) and Haigh et al. (2010) show changes between 2004 and 2007, during the declining phase of the solar cycle, that differ in magnitude and, at some wavelengths, in sign from accepted understanding (Lean, 2000; Lean et al. 1997). The data presented by Haigh et al. (2010) contain decreases in the 320$400 \mathrm{~nm}$ spectral irradiance whose magnitudes are strongly wavelength dependent and which are generally much larger than predicted by the model of Lean (2000). Based on Fig. 1 of Haigh et al. (2010), the decline is roughly $0.5 \mathrm{~W} \mathrm{~m}^{-2}$ when integrated over $320-400 \mathrm{~nm}$. This is similar to the full solar cycle change inferred from the South Polar 320-400 nm surface data, being $1.5-1.8 \%$ of the absolute irradiances in Table 1.

Rapidly varying clouds provide a readily detected attenuation of incoming radiation, but this work showed that South Polar clouds are not obviously correlated with the solar cycle. However, other contributors to the polar atmospheric opacity are conceivable. For example, persistent layers of scatterers such as ice crystals, which are too thin to appear as a readily-seen cloud, could exert a weak influence on the irradiance ratios. Such thin scattering layers could exist over the South Pole, and the attenuation they provide might have varied systematically on the time scale of the 11-year solar cycle during the period of the irradiance measurements. This hypothesis, although speculative, could explain the observed variability in ground-level solar irradiance, including the fact that the best estimate of the percent variation in the visible is larger than that in the UV-A.

\section{Conclusions}

Clouds over the South Pole act both to attenuate and to enhance solar irradiance observed by a ground-based sensor. Averaged over the entire observing period, the overall effect of South Polar clouds is a small attenuation, with the mean measured irradiance being about 5-6\% less than the clearsky value for wavelengths between 320 and $600 \mathrm{~nm}$. The fractional attenuation or enhancement at any instant of time is wavelength dependent, where the percent deviation from the clear-sky irradiance at $400-600 \mathrm{~nm}$ is typically 2.5 times that in the near ultraviolet at $320-340 \mathrm{~nm}$. The occurrence of irradiances in excess of the clear-sky values and the observed wavelength dependence are consistent with radiative transfer calculations for a high-albedo lower surface, fractional cloud cover with the cloud albedo being independent of wavelength, and Rayleigh scattering.

With a 95\% confidence level as the criterion, the mean irradiance ratios and their standard deviations show no linear dependence on year over solstice periods from 1992 to 2008. This indicates the absence of a trend in cloudiness during the duration of the measurements. However, 
Table 6. Percentage change in irradiance ratio for a 100-Unit Change in $10.7 \mathrm{~cm}$ solar radio flux (based on the regression models).

\begin{tabular}{lrrrr}
\hline $\begin{array}{l}\text { Wavelength } \\
\text { band }(\mathrm{nm})\end{array}$ & $\begin{array}{r}\text { Best estimate \% } \\
\text { change in } R(\lambda) \\
(17 \text { years })\end{array}$ & $\begin{array}{r}95 \% \text { Confidence } \\
\text { range } \\
(17 \text { years) }\end{array}$ & $\begin{array}{r}\text { Best estimate \% } \\
\text { change in } R(\lambda) \\
(\text { Omit 2001) }\end{array}$ & $\begin{array}{r}95 \% \text { Confidence } \\
\text { range } \\
(\text { Omit 2001) }\end{array}$ \\
\hline $320-340$ & 2.0 & $1.0-3.0$ & 1.5 & $0.3-2.8$ \\
$340-360$ & 1.7 & $0.9-2.5$ & 1.3 & $0.2-2.4$ \\
$360-400$ & 1.6 & $0.6-2.6$ & 1.7 & $0.3-3.2$ \\
$400-600$ & 2.4 & $0.5-4.3$ & 3.5 & $1.1-6.0$ \\
\hline
\end{tabular}

Table 7. Correlation of standard deviations of irradiance ratios $(\sigma)$ with the $10.7 \mathrm{~cm}$ solar radio flux.

\begin{tabular}{lrrrr}
\hline Variable & $\begin{array}{r}\text { Correlation } \\
\text { with } F_{10.7}(r) \\
(17 \text { years })\end{array}$ & $\begin{array}{r}\text { Probability by } \\
\text { Chance }(P) \\
(17 \text { years })\end{array}$ & $\begin{array}{r}\text { Correlation } \\
\text { with } F_{10.7}(r) \\
(\text { Omit 2001) }\end{array}$ & $\begin{array}{r}\text { Probability by } \\
\text { Chance }(P) \\
(\text { Omit 2001) }\end{array}$ \\
\hline$\sigma(320-340 \mathrm{~nm})$ & -0.16 & 0.55 & -0.45 & 0.08 \\
$\sigma(340-360 \mathrm{~nm})$ & -0.18 & 0.49 & -0.47 & 0.07 \\
$\sigma(360-400 \mathrm{~nm})$ & -0.13 & 0.61 & -0.41 & 0.11 \\
$\sigma(400-600 \mathrm{~nm})$ & -0.17 & 0.52 & -0.41 & 0.12 \\
\hline
\end{tabular}

significant correlations exist between irradiance ratios at all wavelengths studied and the $10.7 \mathrm{~cm}$ solar radio flux, where the quantities are averaged over individual solstice periods. Regressions based on all 17 solstice periods indicate approximate $1.8 \%$ and $2.4 \%$ decreases in ground-level irradiance for the wavelength regions $320-400 \mathrm{~nm}$ and $400-600 \mathrm{~nm}$, respectively, from solar maximum to solar minimum. The associated uncertainty ranges are approximately $0.8-2.7 \%$ for the UV-A and $0.5 \%-4.3 \%$ for the visible.

Changes in extraterrestrial irradiance over the solar cycle surely contribute a portion of the variability deduced at the polar surface for the $320-400 \mathrm{~nm}$ region, although the magnitude of this contribution is uncertain. However, the inferred solar cycle dependence in the $400-600 \mathrm{~nm}$ visible band is too large to be of extraterrestrial origin unless one adopts values at the lowest end of the error range. Uncorrected instrument drifts and discontinuities can always introduce artifacts into a dataset. However, for this to explain the observed behavior, any such unknown problems must have a spurious correlation with the solar cycle. Given the small magnitude of the inferred changes, the uncertainties in the measurements and the limited duration of the dataset, a confirmation of the solar cycle effect based on independent data would be of value.

Acknowledgements. Support for instrument operation and data processing was provided by the National Science Foundation under prime award number OPP-0000373 granted to Biospherical Instruments, Inc. via subcontracts from Raytheon Polar Services Company. The authors thank Guoyong Wen for valuable discussions concerning the extraterrestrial solar irradiance and Germar Bernhard for a thorough and critical reading of the original manuscript.
Edited by: B. Mayer

\section{References}

Bernhard, G. C., Booth, C. R., and McPeters, R. D.: Calculation of total column ozone from global UV spectra at high latitudes, J. Geophys. Res.-Oc. Atm., 108(D17), 4532, doi:10.1029/2003JD003450, 2003.

Bernhard, G., Booth, C. R., and Ehramjian, J. C.: Version 2 data of the National Science Foundation's ultraviolet radiation monitoring network: South Pole, J. Geophys. Res.-Oc. Atm., 109, D21207, doi:10.1029/2004JD004937, 2004.

Bernhard, G., McKenzie, R. L., Kotkamp, M., Wood, S., Booth, C. R., Ehramjian, J. C., Johnston, P., and Nichol, S. E.: Comparison of ultraviolet spectroradiometers in Antarctica, J. Geophys. Res.Oc. Atm., 113, D14310, doi:10.1029/2007JD009489, 2008.

Booth, C. R., Lucas, T. B., Morrow, J. H., Weiler, C. S., and Penhale, P. A.: The United States National Science Foundation's polar network for monitoring ultraviolet radiation, Ultraviolet Radiation in Antarctica: Measurements and Biological Effects, Antarc. Res. Ser., 62, edited by: Weiler, C. S., and Penhale, P. A., American Geophysical Union, Washington, DC, 17-37, 1994.

Cahalan, R. F., Wen, G., Harder, J. W., and Pilewskie, P.: Temperature responses to spectral solar variability on decadal time scales, Geophys. Res. Lett., 37, L07705, doi:10.1029/2009GL041898, 2010.

Frederick, J. E. and Erlick, C.: Trends and interannual variability in erythemal irradiance, 1978-1993, Photochem. Photobiol., 62, 476-484, 1995.

Frederick, J. E. and Erlick, C.: The attenuation of sunlight by high-latitude clouds: spectral dependence and its physical mech- 
anisms, J. Atmos. Sci., 54, 2813-2819, 1997.

Fröhlich, C.: Evidence of a long-term trend in total solar irradiance, Astron. Astrophys., 501, L27-30, doi:10.1051/00046361/200912318, 2009.

Gough, D. O.: Solar interior structure and luminosity variations, Solar Phys., 74, 21-34, 1981.

Grenfell, T. C., Warren, S. G., and Mullen, P. C.: Reflection of solar radiation by the Antarctic snow surface at ultraviolet, visible, and near infrared wavelengths, J. Geophys. Res.-Oc. Atm., 99(D9), 18,669-18,684, 1994.

Haigh, J. D., Winning, A. R., Toumi, R., and Harder, J. W.: An influence of solar spectral variations on radiative forcing of climate, Nature, 467, 696-699, doi:10.1038/nature09426, 2010.

Harder, J. W., Fontenla, J. M., Pilewskie, P., and Richard, E. K: Trends in solar spectral irradiance variability in the visible and infrared, Geophys. Res. Lett., 36, L07801, doi:10.1029/2008GL036797, 2009.

Hicke, J. A., Slusser, J., Lantz, K., and Pascual, F. G.: Trends and interabbual variability in surface UVB radiation over 8 to 11 years observed across the United States, J. Geophys. Res.-Oc. Atm., 113, D21302, doi:10.1029/2008JD009826, 2008.

Kylling, A., Albold, A., and Seckmeyer, G.: Transmittance of a cloud is wavelength dependent in the UV-range: physical interpretation, Geophys. Res. Lett., 24, 397-400, 1997.

Lean, J.: Evolution of the sun's spectral irradiance since the Maunder Minimum, Geophys. Res. Lett., 27, 2425-2428, 2000.

Lean, J. L., Rottman, G. J., Kyle, H. L., Woods, T. N., Hickey, J. R., and Puga, L. C.: Detection and parameterization of variations in solar mid- and near-ultraviolet radiation (200-400 nm), J. Geophys. Res.-Oc. Atm., 102, 29,939-29,956, 1997.

Liao, Y. and Frederick, J. E.: The ultraviolet radiation environment of high southern latitudes: springtime behavior over a decadal timescale, Photochem. Photobiol., 81, 320-324, 2005.
Lindfors, A. and Arola, A.: On the wavelength-dependent attenuation of UV radiation by clouds, Geophys. Res. Lett., 35, L05806, doi:10.1029/2007GL032571, 2008.

Molina, L. T. and Molina, M. J.: Absolute absorption cross-sections of ozone in the 185 to $350 \mathrm{~nm}$ wavelength range, J. Geophys. Res.-Oc. Atm., 91, 14,501-14,508, 1986.

NOAA National Geophysical Data Center: http://www.ngdc.noaa. gov/, last access: 15 September 2010.

Seckmeyer, G., Erb, R., and Albold, A.: Transmission of a cloud is wavelength dependent in the UV-range, Geophys. Res. Lett., 23, 2753-2755, 1996.

Shettle, E. P. and Weinmann, J. A.: The transfer of solar irradiance through inhomogeneous turbid atmospheres evaluated by Eddington's approximation, J. Atmos. Sci., 27, 1048-1055, 1970.

Sloan, T. and Wolfendale, A. W.: Testing the proposed causal link between cosmic rays and cloud cover, Environ. Res. Lett., 3, 024001, doi:10.1088/1748-9326/3/2/024001, 2008.

Svensmark, H.: Influence of cosmic rays on Earth's climate, Phys. Rev. Lett., 81, 5027-5030, doi:10.1103/PhysRevLett.81.5027, 1998.

Svensmark, H.: Cosmoclimatology: a new theory emerges, Astron. Geophys., 48(1), 1.18-1.24, 2007.

Weiler, C. S. and Penhale, P. A. (Eds.): Ultraviolet Radiation in Antarctica: Measurements and Biological Effects, Antarc. Res. Ser., 62, American Geophysical Union, Washington, DC, 257 pp.,1994.

Wild, M.: Global dimming and brightening: A review, J. Geophys. Res.-Oc. Atm., 114, D00D16, doi:10.1029/2008JD011470, 2009.

Willson, R. C.: Total solar irradiance trend during solar cycles 21 and 22, Science, 277, 163-165, 1997.

World Meteorological Organization: Atmospheric Ozone 1985, Global Ozone Research and Monitoring Project Report No. 16, World Meteorological Organization, Geneva, Switzerland, 1985. 